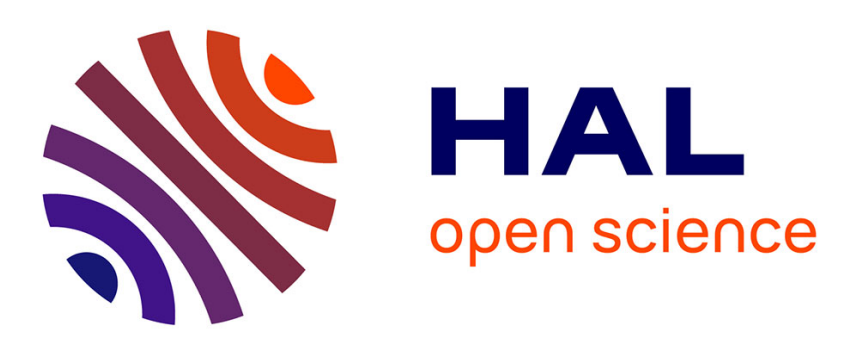

\title{
Pointing gestures produced by toddlers from 15 to 30 months: Different functions, hand shapes and laterality patterns
}

Hélène Cochet, Jacques Vauclair

\section{- To cite this version:}

Hélène Cochet, Jacques Vauclair. Pointing gestures produced by toddlers from 15 to 30 months: Different functions, hand shapes and laterality patterns. Infant Behavior and Development, 2010, 33 (4), pp.431 - 441. 10.1016/j.infbeh.2010.04.009 . halshs-01464466

\author{
HAL Id: halshs-01464466 \\ https://shs.hal.science/halshs-01464466
}

Submitted on 11 Jul 2017

HAL is a multi-disciplinary open access archive for the deposit and dissemination of scientific research documents, whether they are published or not. The documents may come from teaching and research institutions in France or abroad, or from public or private research centers.
L'archive ouverte pluridisciplinaire HAL, est destinée au dépôt et à la diffusion de documents scientifiques de niveau recherche, publiés ou non, émanant des établissements d'enseignement et de recherche français ou étrangers, des laboratoires publics ou privés. 


\title{
Pointing gestures produced by toddlers from 15 to 30 months: Different functions, hand shapes and laterality patterns
}

\author{
Hélène Cochet ${ }^{\mathrm{a}}$, Jacques Vauclair ${ }^{\mathrm{a}, \mathrm{b}, *}$ \\ a Center for Research in the Psychology of Cognition, Language \& Emotion, France ${ }^{1}$ \\ ${ }^{\mathrm{b}}$ Institut Universitaire de France, France
}

\section{A R T I C L E I N F O}

\section{Article history:}

Received 14 October 2009

Received in revised form 27 January 2010

Accepted 23 April 2010

\section{Keywords:}

Toddlers

Pointing gestures

Imperative-declarative

expressive-declarative informative

functions

Hand shapes

Handedness

\begin{abstract}
A B S T R A C T
Three experimental designs were implemented in day nurseries in order to elicit imperative, declarative expressive, and declarative informative pointing gestures (Tomasello, Carpenter, \& Liszkowski, 2007) among a population of 48 toddlers aged 15-30 months. Several features were recorded for each situation, including gesture form, gaze direction, and vocalizations. A unimanual reaching task was also administered, in order to compare laterality patterns for each type of gesture. Main results revealed that imperative gestures were associated with whole-hand pointing, whereas declarative gestures were more frequently characterized by an extended index finger. Moreover, declarative gestures were more frequently accompanied by vocalizations than imperative gestures were. Finally, different degrees of manual preference were observed, especially for informative pointing gestures, which tended to be more right-handed than reaching actions. Results of the study are discussed in relation to the nature and development of each kind of pointing gesture.
\end{abstract} (c) 2010 Elsevier Inc. All rights reserved.

\section{Introduction}

Infants start to communicate intentionally through gestures toward the end of their first year (e.g., Butterworth \& Morissette, 1996; Camaioni, Perucchini, Bellagamba, \& Colonnesi, 2004). In addition to their pragmatic impact (gestures vastly increase communicative resources), communicative gestures also play a key role in the early development of socialcognitive abilities (e.g., Carpenter, Nagell, \& Tomasello, 1998) and serve as a foundation for the development of language (e.g., Iverson \& Goldin-Meadow, 2005; Rowe \& Goldin-Meadow, 2009). The predictive and facilitative relationship between gesture and speech has mainly been highlighted in the context of the pointing gesture (e.g., Pizzuto \& Capobianco, 2005). The latter shares common mechanisms with speech, as it enables children to interact with adults and to communicate their intentions, requests and feelings about a specific referent. It is a complex gesture, whose meaning depends on the nature of the concrete object or situation that is being referred to, as well as on the circumstances in which the gesture is used (e.g., Tomasello, Carpenter, \& Liszkowski, 2007).

Moreover, there is considerable variability in the expression of pointing gestures, especially when we focus on their function. In an early study, Bates, Camaioni, and Volterra (1975) made a distinction between protoimperative and protodeclarative gestures, the former being defined as the "use of the adult as a means to a desired object" and the latter as the

\footnotetext{
* Corresponding author at: Department of Psychology, University of Provence, 29, av. Robert Schuman, 13621 Aix-en-Provence Cedex 1, France. Fax: +33442389170.

E-mail addresses: helene.cochet@univ-provence.fr (H. Cochet), Jacques.Vauclair@univ-provence.fr (J. Vauclair).

1 http://sites.univ-provence.fr/wpsycle/index.html.
} 
"use of an object as the means to obtaining adult attention" (p. 209). Both protoimperative and protodeclarative gestures were thus initially described as instrumental acts towards some physical or social goal. Several authors later defended the idea that infants' early pointing aimed at gaining positive emotional reactions to the self rather than directing the attention of others to external entities and that neither imperative nor declarative pointing involved the understanding of others' attention (e.g., Moore \& Corkum, 1994; Moore \& D’Entremont, 2001; Racine \& Carpendale, 2007).

By contrast, other researchers opposed imperative and declarative gestures, arguing that declarative pointing reveals an early form of psychological understanding (e.g., Pika, 2008; Tomasello, 1995). Children would use imperative pointing to ask someone to do something for them (e.g., the child points to an unreachable object as a request to be given it), whereas declarative gestures would be used to direct the addressee's attention to a referent for reasons other than achieving egocentric goals (e.g., children point to the plane they have just seen in the sky so that their parents can see it, too, and share in their enthusiasm). Declarative pointing would thus demonstrate that infants understand others as attentional and intentional agents (e.g., Liszkowski, Carpenter, Henning, Striano, \& Tomasello, 2004; Liszkowski, Carpenter, \& Tomasello, 2007). More recently, Tomasello et al. (2007) distinguished between declarative expressive gestures, when the child seeks to share interest in an object, event or location, and declarative informative gestures, when the child cooperates with adults and gives them some information they need (see also Liszkowski, Carpenter, Striano, \& Tomasello, 2006).

Evidence from autistic children, who have problems with declarative communication, but are able to produce and understand imperative gestures (e.g., Camaioni, 1997; Camaioni, Perucchini, Muratori, \& Milone, 1997), suggests that imperative and declarative pointing gestures are associated with different underlying social and cognitive mechanisms. Studies of nonhuman primates support the notion of a split between imperative and declarative communication, as the gestures produced by these species also seem to lack the declarative function (e.g., Leavens, Hopkins, \& Bard, 1996), although there have been a few reports of apparently declarative gestures in language-trained apes (see Leavens, 2009). It has been argued that early emotional bonding with caregivers plays a role in the ability to develop declarative communication (Leavens, 2009), given that the few declarative gestures recorded in nonhuman primates were produced by apes that had experienced close emotional ties with humans. However, declarative gestures may also involve more complex social and cognitive skills, which are necessary for the development of speech, such as theory of mind and cooperation abilities (e.g., Liszkowski, 2005). A study of 12-15-month-old toddlers revealed that the production of declarative pointing gestures, but not imperative gestures, was linked to the understanding of adults' intentions (Camaioni et al., 2004). Imperative pointing gestures, even though they are intentional and referential, may be less cognitively demanding. The process involved in controlling these gestures, at least at a very early stage, may be similar to operant conditioning: children's pointing gestures are followed by adults' giving them the desired object (positive reinforcement). This would lend meaning to the gestures and enable young children to "operate" on the environment.

The question then arises as to whether imperative and declarative pointing gestures have different origins. Vygotsky (1988) argued that pointing gestures develop out of failed reaching. However, although this idea is consistent with the request function of pointing gestures (reaching actions and imperative pointing gestures share the same ultimate goal, i.e., obtaining a desired object), it seems unlikely that declarative pointing emerges from reaching actions, as illustrated by the following examples. Try to imagine what infants do when they want their mother (or father) to give them the biscuits that are out of reach on the table. They begin by initiating the action of reaching for and taking the biscuits. The mother then understands that they want some biscuits and may decide to give them some. By this means, children learn about the relationship between their own actions and the effects of these actions on adults. Tomasello and Call (1997) refer to this process, by which an action becomes a communicative signal thanks to the partner's reaction, as ontogenetic ritualization. But what happens when children are surprised by a particular event, such as a cat walking through the garden, which their mother has not seen? Rather than trying to reach out and take hold of the cat, the children may instead want to direct the adult's attention to it and provoke some enthusiasm. To find a way of communicating in this specific context, children have no choice but to dip into the gestural repertoire that is already stored in their memory. And what children are most likely to have seen in previous declarative situations is adults producing indexical pointing gestures, in order to direct their attention to some external referent. Imitation, and even deferred imitation, might thus play a key role in the development of declarative pointing. A longitudinal study has shown that deferred imitation in 9-month-old infants was the strongest predictor of communicative gesture production measured 5 months later (Heimann et al., 2006). However, the authors unfortunately did not mention whether they distinguished between imperative and declarative gestures. And more globally, the idea of distinct origins for imperative and declarative pointing remains hypothetical, as there is no direct evidence of the learning processes through which the different kinds of pointing are acquired.

A more empirically testable distinction between imperative and declarative pointing may concern hand shape variability. Not only do pointing gestures serve different functions, but they also take different forms, and this has been a source of disagreement between researchers regarding the definition of pointing itself. While all researchers agree that pointing is a communicative gesture through which a gesturer directs the addressee's attention to a specific referent, some of them consider that it can be produced either with the extended index finger or with the whole hand (e.g., Brooks \& Meltzoff, 2008; Gullberg, de Bot, \& Volterra, 2008; Krause \& Fouts, 1997; Liszkowski, Carpenter, \& Tomasello, 2008), whereas for others, pointing is restricted to index extension (e.g., Blake, O'Rourke, \& Borzellino, 1994; Butterworth, Franco, McKenzie, Graupner, \& Todd, 2002; O’Neill, Bard, Linnell, \& Fluck, 2005).

In the present study, the broader of the two definitions was adopted and we investigated whether toddlers use different hand shapes for different functions. We implemented three experimental designs at day nurseries to elicit imperative, 
declarative expressive and declarative informative pointing gestures (Tomasello et al., 2007). If imperative gestures do indeed evolve from reaching actions, we would expect them to be characterized by a similar form, that is, whole-hand pointing. By contrast, declarative gestures, which might develop through imitation, should be more closely associated with index-finger pointing.

In addition, as communication involves a wide range of behaviors, both vocal and nonvocal, we described several other features of gestures in the three different experimental situations. Firstly, in order to compare interactions between gestural and vocal systems in each situation, we distinguished between gestures accompanied by vocalizations and gestures produced in isolation. Moreover, language level was assessed in order to examine whether declarative gestures have a closer relationship with language development than imperative gestures do. Gaze direction patterns were also studied, as gaze alternation between addressee and referent is usually regarded as one of the markers of intentional communication (e.g., Leavens, 2009). Pointing duration was measured, too. We hoped that all these variables would help us to identify the nature of children's intentions when producing imperative, declarative expressive, and declarative informative pointing gestures.

We also focused on manual preferences, as an indicator, albeit indirect, of cerebral asymmetries for gestural communication. While there is no longer any doubt as to the right-hand bias for pointing gestures (Bates, O'Connell, Vaid, Sledge, \& Oakes, 1986; Blake et al., 1994; Young, Lock, \& Service, 1985), the question of whether imperative, declarative expressive, and declarative informative pointing gestures present different laterality patterns has yet to be answered. Our goal was therefore to compare the involvement of the left cerebral hemisphere between these three situations. Moreover, in order to investigate the contrast with handedness for manipulative actions, a simple unimanual task was included in the present study, in which children had to reach for and grasp objects. The comparison of hand preferences for reaching actions and for the different pointing gestures might help to shed light on the hypothesis of distinct origins for imperative and declarative pointing. Noncommunicative manual actions have previously been reported as being less right-handed than pointing gestures in toddlers (Bates et al., 1986; Vauclair \& Imbault, 2009). If imperative pointing gestures originate from reaching actions, we would expect to observe differences in the degree of hand preference between imperative and declarative gestures: imperative pointing would be less right-handed than declarative pointing.

Our hypotheses mainly concerned differences between imperative and declarative gestures, as it is more difficult to infer potential differences between declarative expressive and declarative informative pointing gestures. With declarative expressive pointing, children seek to share their interest in a specific referent, expecting the addressee to attend to this referent and show some enthusiasm (Liszkowski, 2005). Expressive pointing does not seem to require the same cooperative abilities as informative pointing. Little, however, is currently known about the specific characteristics of declarative informative pointing, other than that it involves the understanding of others as agents with informational states, and the motivation to cooperate with and help a communication partner, without any immediate benefit to oneself (Liszkowski et al., 2006). Our study might therefore yield some interesting information about the distinguishing features of these two kinds of declarative pointing.

\section{Method}

\subsection{Participants}

Forty-eight children (23 girls and 25 boys) attending four different daycare centers took part in the study. They were aged between 14.6 and 31 months $(M=23.9 ; S D=3.7)$.

\subsection{Procedure}

Depending on the daycare center, children were seen either in isolation in a separate room or in the main room but apart from the other children. All sessions were videotaped. Three experimenters were present in the room, including one standing behind the camera who noted down the behaviors as they were recorded. The two others interacted with the children and participated in the different situations described hereafter. Each participant in turn was seated at a rectangular table, with one of the experimenters sitting opposite him/her. Children had met the experimenters at least once before the day of the experiment and every session began with a short warming-up period so that the children did not feel insecure. Three pointing tasks and one unimanual grasping task were administered. Children undertook five trials for each task and the order of task presentation (unimanual grasping and pointing) was alternated across participants. Between the different tasks, the experimenter interacted with the children in order to maintain their attention.

For the unimanual grasping task, participants had to grasp small, different-colored balls that the experimenter put down on the table in front of them. All the children successfully performed the five trials of the grasping task.

The pointing tasks, presented in random order, were designed to elicit imperative, declarative expressive, and declarative informative pointing gestures (Tomasello et al., 2007). In each of the following situations, the experimenter reacted immediately and continuously for 5 s once the child pointed toward the specific referent, then the trial was over.

For the imperative pointing task (I), we used five attractive toys. The experimenter sitting opposite the child, between 1 and $1.5 \mathrm{~m}$ away from him/her, handled the object first. She showed interest in the toy, then gave it to the child for a few seconds before taking it back. The experimenter then put the object on the table, beyond the child's reach. The experimenter looked silently at the child for $15 \mathrm{~s}$ and gave the toy to the child if the latter produced a pointing gesture. If the child did 
not react, the experimenter said "Look at this! Isn't it pretty?" or something similar, and waited again for a further 15 s. The experimenter then gave the toy to the child.

For the declarative expressive task (DE), we used different-colored drawings of faces on $30 \mathrm{~cm} \times 30 \mathrm{~cm}$ boards, between 1 and $1.5 \mathrm{~m}$ away from the child. The first experimenter (E1) sat opposite the child and interacted and played with him/her. The other experimenter (E2), hiding behind E1, suddenly held up one of the drawings twice, so that the child could see it but not E1. If the child pointed toward the drawing, the experimenter emoted positively about it for a few seconds. If the child did not react within $15 \mathrm{~s}$ once the board had disappeared, E2 held up the picture again in order to trigger a pointing gesture. The aim of the task was to create a sudden and unexpected event that the child would want to share with E1.

For the declarative informative task (DI), we used everyday objects that we thought would not be particularly attractive to the children, or at least, not as interesting as the toys used for the imperative task (e.g., a pen, a packet of lozenges, keys). E1 put the object down on the table (in front of the children), but out of reach (approximately $0.5 \mathrm{~m}$ away from them) and left the room. E2 came in, covered the object with a magazine so that the child could still see the object protruding from under it, and left. E1 came back and started searching for the object silently. If the child pointed, the experimenter retrieved the object and thanked the child for his/her help. If no pointing gestures were produced within $15 \mathrm{~s}$, E1 asked "Where are my keys?", or an equivalent question, and waited for the child's reaction for a further $15 \mathrm{~s}$.

\subsection{Measures}

In order to assess the children's language level, parents were asked to fill in the French adaptation (Kern, 2003) of the MacArthur Communicative Development Inventories (MCDI; Fenson et al., 1993). For the sake of comparison, we used the "Words and Sentences" questionnaire, designed for children aged between 16 and 30 months, to assess all the participants, instead of combining it with the one aimed at children between 8 and 16 months. The language score corresponded to the total number of words the children had in their vocabulary, according to their parents. Scores varied between 2 and 581 $(M=201 ; S D=162)$ and significantly correlated with age $(r(42)=.63 ; p<.001)$.

Regarding the children's visual behavior, we distinguished between gaze directed toward the referent (the object or event being pointed at), gaze directed toward the experimenter, and gaze alternating between experimenter and referent. The duration of the pointing gesture was also recorded. Moreover, we noted whether or not the gesture was accompanied by vocalizations. The latter, which could consist of any kind of vocal sound, had to be produced at the precise moment of the pointing gesture. Finally, the gesture was deemed to be a whole-hand point if all the fingers were extended, without any finger clearly distinct from the others, and an index-finger point when the index finger was extended and the other fingers were tightly or more lightly curled.

To measure handedness, we calculated individual handedness index scores (HI) with the formula $(R-L) /(R+L)$, where $R$ and $\mathrm{L}$ stand for the total number of right- and left-hand responses. The HI values lay along a continuum from -1 to 1 , with the $+1-$ sign indicating hand-preference direction and the absolute value reflecting hand-preference strength.

\subsection{Reliability}

All the behaviors we studied were first coded in real time by one of the experimenters. Two other experimenters then separately coded all the video recordings at the end of all the experiments in order to check the initial coding. There was $100 \%$ agreement between coders on hand preference, $100 \%$ on vocalizations, $98 \%$ on point duration, $86 \%$ on visual behavior and $92 \%$ on hand shapes. When they disagreed over the interpretation of a behavior, the video was shown to a research assistant who settled the question.

\section{Results}

To present our results as clearly as possible, we focus, in turn, on the number of pointing gestures the infants produced, the form of these gestures, manual preference, vocal and visual behaviors, and finally, the duration of the pointing gestures. We also report how these different variables were related to age and language level.

\subsection{Number of pointing gestures}

Forty-seven of the 48 children produced pointing gestures. There were five trials for each of the three pointing situations, but children only produced a pointing gesture in $52 \%(S D=24.5 \%)$ of them, that is, an average of 7.8 gestures across the 15 trials. Whereas age did not correlate with the overall number of pointing gestures produced, it did correlate with the proportion of declarative informative gestures $(r=.47 ; p<.001)$, indicating that as children grew older, they produced more informative pointing gestures. 


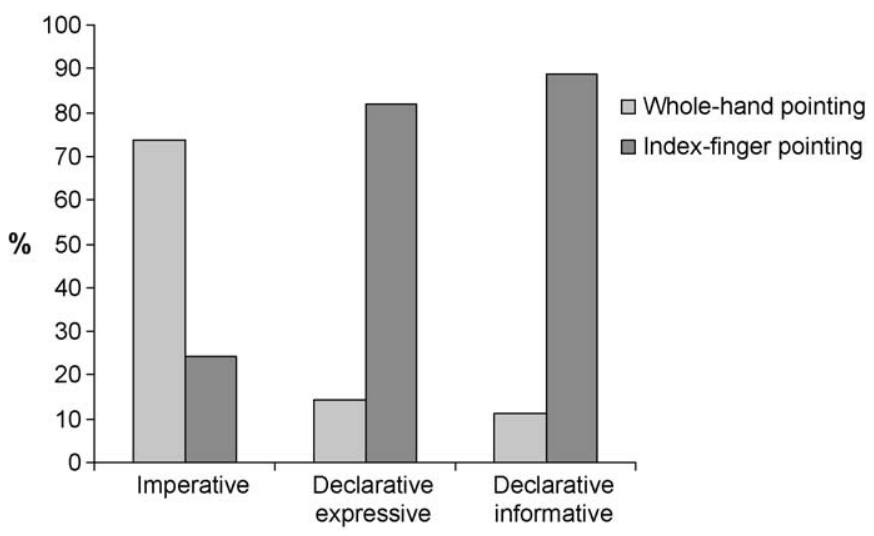

Fig. 1. Mean proportions of whole-hand and index-finger pointing gestures produced in each pointing situation.

Table 1

Comparison of the mean proportions of whole-hand and index-finger pointing gestures for each gesture function.

\begin{tabular}{llll}
\hline & Whole-hand & Index-finger & $t$-Test \\
\hline Imperative pointing & $73.6 \% \pm 31.5$ & $24.2 \% \pm 31.9$ & $t(42)=7.14 ; p<.001$ \\
Declarative expressive & $14.5 \% \pm 32.9$ & $81.9 \% \pm 35.0$ & $t(30)=-7.70 ; p<.001$ \\
Declarative informative & $11.1 \% \pm 26.9$ & $88.9 \% \pm 26.9$ & $t(33)=-11.75 ; p<.001$ \\
\hline
\end{tabular}

\subsection{Hand shape}

On average, $36.9 \%$ of the gestures produced by children took the form of whole-hand pointing $(S D=31.5)$ and $61.6 \%$ the form of index-finger pointing $(S D=32.1)$. The remaining $1.5 \%(S D=5.8)$ were made up of other forms. ${ }^{2}$ Fig. 1 shows the mean proportions of whole-hand and index-finger gestures produced for each pointing situation.

Imperative gestures were more frequently associated with whole-hand pointing, whereas declarative gestures, both expressive and informative, were more frequently associated with index-finger pointing (see Table 1 for $t$-tests).

Reciprocally, a significantly higher number of index-finger pointing gestures were produced in declarative situations than in the imperative one, $t(28)=-6.17 ; p<.001$ for declarative expressive pointing and $t(29)=8.44 ; p<.001$ for declarative informative pointing. Conversely, whole-hand pointing gestures were more frequently used in the imperative situation than in the declarative expressive, $t(28)=6.48 ; p<.001$, and declarative informative ones, $t(29)=-8.08 ; p<.001$.

Both whole-hand and index-finger gestures were more frequently produced with the right hand than with the left hand, $t(40)=2.77 ; p<.01$ and $t(41)=6.78 ; p<.001$. However, when we compared the mean handedness indices (MHI) of children who produced both types of gestures $(N=34)$, whole-hand pointings $(\mathrm{MHI}=0.39)$ tended to be less right-handed than index-finger pointings $(\mathrm{MHI}=0.67), t(34)=-1.74 ; p=.086$.

Finally, the proportions of index-finger gestures and whole-hand gestures were correlated with age $(r=.58 ; p<.001$ and $r=-.59 ; p<.01)$. As they grew older, children produced more index-finger pointing gestures and fewer whole-hand gestures (see Fig. 2). The proportion of index-finger gestures also correlated with language level $(r=.41 ; p<.01)$, as did the proportion of whole-hand gestures $(r=-.43 ; p<.001)$. However, this relation was explained by the correlation between age and language level. After controlling for age, no correlation was found between language level and the proportion of index-finger pointing gestures (for age: $\beta=0.57 ; p<.01$; for language level: $\beta=0.059 ; n s$ ).

The correlation between age and gesture form was also investigated for each pointing situation. The same relation was observed for declarative expressive and declarative informative gestures: as children grew older, they produced more indexfinger pointing gestures $(r=.43 ; p<.05 ; r=.51 ; p<.01)$ and fewer whole-hand gestures $(r=-.41 ; p<.05 ; r=-.51 ; p<.01)$. However, there was no significant correlation between age and the form of imperative gestures $(r=.24$; $n s$ for the proportion of index-finger gestures; $r=.25$; $n s$ for the proportion of whole-hand gestures).

\subsection{Handedness}

Table 2 and Fig. 3 illustrate the mean handedness indices (MHI) associated with the different manual activities we studied.

MHI for reaching actions tended to be lower than MHI for pointing gestures, $t(47)=-1.77 ; p=.079$. We then distinguished between the three different pointing situations. In order to compare MHIs, participants who did not produce the two types

\footnotetext{
2 These included any forms that did not match the earlier description of index-finger or whole-hand pointing gestures (e.g., extending the arm and fist toward an object, without any extended fingers).
} 


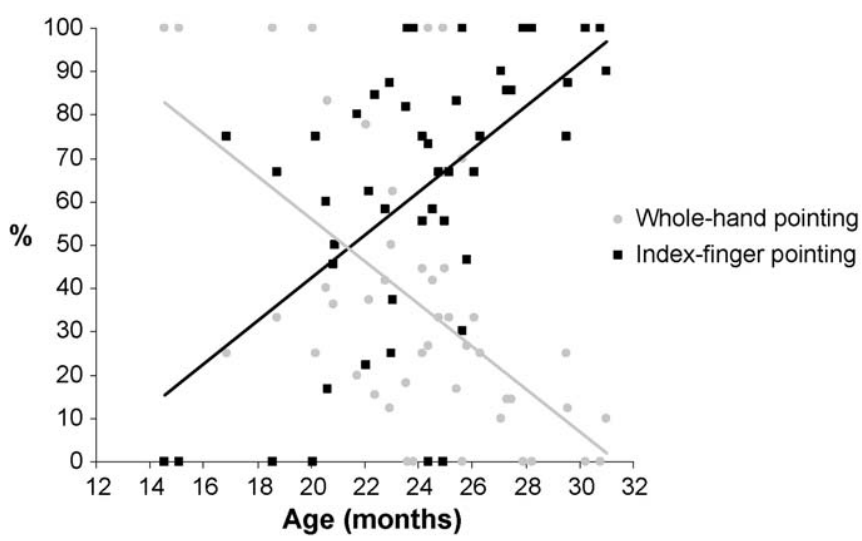

Fig. 2. Proportions of whole-hand and index-finger pointing gestures produced as a function of the children's age.

Table 2

Mean handedness index (MHI) associated with different manual activities.

\begin{tabular}{llll}
\hline & MHI & $S E$ & $N$ \\
\hline Reaching actions & 0.32 & 0.10 & 48 \\
Pointing gestures & 0.55 & 0.08 & 47 \\
Imperative pointing gestures & 0.43 & 0.11 & 42 \\
Declarative expressive gestures & 0.46 & 0.13 & 30 \\
Declarative informative pointing gestures & 0.70 & 0.08 & 33 \\
Whole-hand pointing gestures & 0.37 & 0.12 & 41 \\
Index-finger pointing gestures & 0.62 & 0.09 & 40 \\
\hline
\end{tabular}

of pointing involved in the comparison were excluded from the analysis (the number of excluded participants varied for each comparison). There was no difference either between $\mathrm{MHI}$ for reaching actions and $\mathrm{MHI}$ for imperative pointing, $t(42)=-1.01 ; n s$, or between MHI for reaching actions and MHI for declarative expressive pointing, $t(30)=-0.62 ; n s$, but $\mathrm{MHI}$ for declarative informative pointing tended to be higher than MHI for reaching actions, $t(33)=-1.96 ; p=.054$. None of the correlations between $\mathrm{MHI}$ for reaching actions and $\mathrm{MHI}$ for pointing gestures were significant, whatever situation was considered.

There was no significant difference between MHI for imperative and declarative expressive gestures, $t(28)=-0.46 ; n s$, between MHI for imperative and declarative informative gestures, $t(29)=-1.54$; $n s$, or between MHI for declarative expressive and declarative informative gestures, $t(22)=-0.64 ; n s$. Pearson correlation coefficients confirmed these results, as the MHIs associated with the different pointing gesture situations significantly correlated with each other (imperative and declarative expressive gestures: $r=.49 ; p<.01$, imperative and declarative informative gestures: $r=.53 ; p<.01$, declarative expressive and declarative informative gestures: $r=.58 ; p<.01$ ).

Lastly, MHIs, whether they were associated with reaching actions or with pointing gestures, were correlated neither with the language test score nor with age.

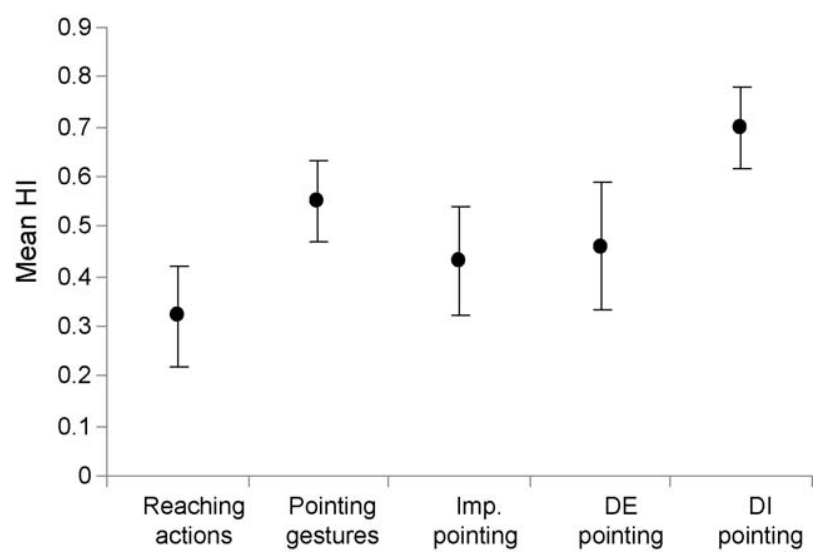

Fig. 3. Mean handedness index $( \pm S E)$ associated with reaching actions and pointing gestures (imperative, declarative expressive and declarative informative). 
Table 3

Mean proportions $( \pm S D)$ of the different visual behaviors observed in each pointing situation.

\begin{tabular}{llcc}
\hline & Referent & Experimenter & Referent/experimenter alternation \\
\hline Imperative pointing & $86.0 \% \pm 27.4$ & $1.6 \% \pm 7.2$ & $12.4 \% \pm 27.2$ \\
Declarative expressive & $78.7 \% \pm 27.5$ & $6.1 \% \pm 20.8$ & $15.2 \% \pm 22.8$ \\
Declarative informative & $44.9 \% \pm 37.86$ & $15.8 \% \pm 25.4$ & $39.3 \% \pm 36.4$ \\
\hline
\end{tabular}

Table 4

Mean proportions $( \pm S D)$ of pointing gestures according to duration and function.

\begin{tabular}{llr}
\hline & $<1 \mathrm{~s}$ & \multicolumn{1}{c}{$1-2 \mathrm{~s}$} \\
\hline Imperative pointing & $65.7 \% \pm 39.6$ & $25.8 \% \pm 29.6$ \\
Declarative expressive & $46.1 \% \pm 41.6$ & $28.3 \% \pm 31.9$ \\
Declarative informative & $36.8 \% \pm 33.8$ & $35.1 \% \pm 31.2$ \\
\hline
\end{tabular}

\subsection{Vocal behavior}

On average, $44.2 \%$ of the pointing gestures were accompanied by vocalizations $(S D=35.1)$ and $55.8 \%$ were not $(S D=35.1)$. The proportion of gestures accompanied by vocalizations tended to be only weakly correlated with language level $(r=.30$; $p=.053$ ), indicating that children with a high language test score did not really vocalize more than children with a lower score. The production of vocalizations seemed to depend more on the type of pointing gesture. In the imperative situation, only $21.1 \%$ of the pointing gestures were produced simultaneously with vocalizations, whereas $67.6 \%$ and $58.3 \%$ of declarative expressive and declarative informative gestures were. Imperative gestures were therefore more frequently produced without vocalizations, $t(41)=-8.11 ; p<.001$. Declarative expressive gestures were more frequently accompanied by vocalizations, $t(30)=3.42 ; p<.01$, whereas declarative informative gestures were produced with and without vocalizations equally often, $t(33)=1.57$; $n$ s. The mean proportion of declarative gestures accompanied by vocalizations was higher than that of imperative gestures, $t(28)=-4.14 ; p<.001$ for declarative expressive pointing and $t(28)=-3.35$; $p<.01$ for declarative informative pointing. There was no difference between declarative informative and declarative expressive pointing, $t(22)=0.77 ; n s$.

\subsection{Visual behavior}

Children alternated their gaze between the referent and the experimenter in $20.4 \%$ of cases $(S D=22.2)$. They looked solely at the experimenter in $7.4 \%$ of cases $(S D=12.8)$ and solely at the referent of the pointing gesture in $72.2 \%$ of cases $(S D=24.9)$. We then compared the types of visual behavior associated with the three different pointing situations (see Table 3 ).

The proportion of gaze alternations between referent and experimenter was significantly higher for declarative informative pointing than for imperative pointing, $t(29)=2.33 ; p<.05$, and declarative expressive pointing, $t(22)=3.12 ; p<.01$. There was no difference between imperative pointing and declarative expressive pointing for the proportion of gaze alternations, $t(28)=0.83$; $n s$. The proportion of gazes directed solely at the referent was significantly lower for declarative informative pointing than for imperative pointing, $t(29)=-3.91 ; p<.001$, and declarative expressive pointing, $t(22)=-3.85 ; p<.001$. There was no difference between imperative pointing and declarative expressive pointing, $t(28)=1.51 ; n s$.

\subsection{Gesture duration}

A majority of gestures lasted less than $1 \mathrm{~s}(52.8 \% \pm 30.9)$. However, when we distinguished between the different types of pointing (see Table 4), results revealed that the proportion of gestures lasting less than 1 s only rose above $50 \%$ for imperative gestures.

Student's t-tests showed that, for gestures lasting less than $1 \mathrm{~s}$, imperative pointing gestures were significantly more frequent than declarative informative ones, $t(29)=2.81 ; p<.01$, and tended to be more frequent than declarative expressive ones, $t(28)=1.89 ; p=.064$. Regarding gestures lasting more than $2 \mathrm{~s}$, declarative expressive and declarative informative pointing gestures were more frequent than imperative ones, $t(28)=-2.22 ; p<.05$ and $t(29)=-2.80 ; p<.01$. There was no difference between declarative informative and declarative expressive pointing, for any gesture duration.

As the experiments were conducted in different testing conditions depending on the daycare center - in isolation vs. in a group setting - analyses of variance were performed for each dependent variable to investigate the potential influence of different environments. These procedural variations were found not to have influenced any of the behaviors we studied. Finally, the results did not reveal any effect of gender on any of the different variables.

\section{Discussion}

The aim of the present study was to investigate different types of pointing gesture and to characterize their development in terms of form, duration, gaze, manual laterality and vocalizations. When we focused on gesture duration, hand shape 
and vocalizations, our results suggested a distinction between imperative and declarative (both expressive and informative) pointing gestures. In terms of handedness and visual behavior, however, imperative and declarative expressive gestures seemed to contrast with declarative informative pointing.

On the whole, declarative pointing gestures were more frequently accompanied by vocalizations than imperative gestures were. Declarative communicative gestures were thus more tightly interconnected with the vocal system than imperative gestures. The facilitative role of gestures in language development may therefore concern declarative rather than imperative pointing, as suggested in previous findings (e.g., Camaioni et al., 2004). It would be interesting to distinguish between different types of vocalizations in order to investigate whether imperative and declarative gestures are characterized by specific vocalizations. For example, whining vocalizations might be associated with imperative gestures, whereas words or pseudowords might be produced more frequently in declarative situations.

Our results revealed that, on average, $44.2 \%$ of pointing gestures were accompanied by vocalizations, whereas in another study we conducted of toddlers of about the same age as those in the present sample, $90 \%$ of spontaneous pointing gestures were accompanied by vocalizations (Cochet \& Vauclair, in press). However, for the purposes of that study, we deemed that a gesture was accompanied by vocalizations if these occurred within a two-second interval, whereas in the present study, vocalizations and gestures had to be produced at exactly the same time, in order for them to be regarded as simultaneous. Although these different methodological choices probably account for the difference in the proportion of "vocal gestures" between the two studies, the experimental context may also explain this result, as the high percentage of accompanying vocalizations was observed in a natural setting, during free play. The more natural the situation is, the more likely children are to vocalize, and this should be taken into account in developmental studies using experimental designs.

The measure of pointing duration led to another distinction between declarative and imperative gestures: declarative gestures lasted longer than imperative ones, which might reflect infants' wish to maintain interactions in the declarative situation. However, this result is difficult to interpret, as gesture duration depends on a variety of factors, including the time taken by the adult to respond to the child's pointing. For example, if the adult reacted more quickly to a child's request than to a child's comment about a referent, that child might curtail his/her imperative pointing but prolong the declarative gesture. In our study, the experimenter reacted as soon as the children pointed in each of the situations, so the response latencies of the adult to the infants' points were probably equivalent across conditions. But this variable was not recorded and needs to be controlled in future studies before being able to properly interpret this kind of results.

The difference in hand shapes appeared to provide the most persuasive evidence for a distinction between imperative and declarative pointing gestures. Imperative gestures were more frequently associated with whole-hand pointing than with index-finger pointing, whereas declarative gestures, both expressive and informative, were more frequently associated with index-finger pointing. Reciprocally, index-finger pointing gestures were produced more frequently in declarative situations than in the imperative one, while whole-hand pointings were more frequently used in the imperative situation. These results are similar to those reported by Franco and Butterworth (1996) in a study comparing the use of pointing and reaching gestures in 10-18-month-old toddlers, even though they used different terms to describe the gestures. What these authors defined as a pointing gesture (traditional index-finger pointing) was used with a declarative function from the outset, whereas in imperative situations, children produced "reaching" gestures, described by the authors as communicative, open-hand gestures.

Taken together, our results suggest that imperative and declarative pointing gestures emerge from different processes, thus confirming our hypothesis. Imperative pointing appears to originate from noncommunicative reaching actions, acquiring a communicative function through a process of ontogenetic ritualization (Tomasello \& Call, 1997), as children learn that their gestures produce specific effects on adults. By contrast, imitation would appear to be the learning process involved in the emergence of declarative pointing, as the later was characterized by index extensions in both expressive and informative situations.

The relation between age and gesture form also supports the hypothesis of separate origins for imperative and declarative gestures. As children grew older, they produced an increasing number of index-finger pointing gestures, at the expense of whole-hand gestures, which were used less and less. However, whereas this relation was observed for both expressive and informative types of declarative gestures, the form of imperative gestures did not change as a function of age. Although they were able to use index-finger pointing, children continued to use whole-hand pointing in the imperative situation. This result emphasizes the close relationship between children's objectives and the hand shapes they use: when they are trying to obtain an object, they adopt the hand shape that will allow them to take hold of it. However, this does not mean that imperative pointing is nothing more than the initiation of the grasping action, as many clues, including gaze, posture and vocalizations, attested to the intentional and referential nature of the gesture.

Pointing gestures produced by adults can also take various forms, depending on the situation or the focus of the conversation (Kendon \& Versante, 2003; Wilkins, 2003). Nonetheless, the use of pointing gestures by children and adults is quite different: adults' pointing is produced to reinforce the discourse, generally by indicating the referent of a deictic word, whereas infants' pointing is the main component of their communicative signal. Comparing children's and adults' gestures is therefore a delicate matter, and although it seems likely that adults point with all fingers extended when requesting an object, no study so far has actually demonstrated this use of whole-hand pointing gestures in imperative situations.

Moreover, even though the hand shape associated with imperative pointing did not change as the children grew older, there may have been a gradual shift in the underlying cognitive abilities. Social understanding is not an all-or-nothing affair 
and might indeed involve different levels of understanding (Carpenter et al., 1998). The initial objective of infants' imperative pointing is to influence the adult's behavior. Subsequently, more complex skills develop (in relation to the emergence of declarative pointing) and children's imperative gestures, though still produced to obtain something for themselves, are then probably intended to influence the adult's goals and attention (Liszkowski et al., 2006).

Finally, the distinction between whole-hand and index-finger pointing deserves a more thorough investigation. In the present study, "index-finger gesture" characterized a hand shape in which the index finger was extended and the other fingers either tightly or more lightly curled. It would be interesting to distinguish between the latter to find out whether they are produced in different contexts. Image software would enable measurements to be made of hand shapes on still images extracted from video sequences.

Our results revealed another contrast besides the one between imperative and declarative pointing. With regard to handedness and visual behavior, imperative and declarative expressive pointing seemed to contrast with declarative informative pointing. Gaze alternations between referent and experimenter were significantly more frequent in the declarative informative situation than in the imperative and declarative expressive ones. In the informative situation, the experimenter pretended that she had lost a specific object, which was visible to the children. The latter then pointed toward the object in order to show the adult where it was, indicating that they knew the experimenter lacked this information. Gaze alternation was more frequent in informative pointing because in this situation, children had to establish the relation between the object and the adult and they particularly needed to check the latter's informational state (Liszkowski et al., 2006).

Informative gestures also differed from the other two pointing gestures on hand-preference patterns. But before we come to that, we first need to discuss overall results for handedness. Our findings highlighted the difference between manipulative actions and communicative gestures, as none of the correlations between handedness indices (HI) for reaching actions and $\mathrm{HI}$ for pointing gestures were significant, whereas $\mathrm{HI}$ for the different kinds of pointing gestures all correlated with each other. Moreover, pointing gestures tended to be more right-handed than reaching actions, confirming results of a study by Bates et al. (1986) of 13-28-month-old toddlers.

These results suggest that hand preference for communicative gestures develops independently from handedness for manipulative actions. It has been argued that these different patterns may be related to distinct neurobiological substrates in the left cerebral hemisphere. In particular, Vauclair and Imbault (2009) have postulated the existence of a specific communication system in the left cerebral hemisphere controlling both gestural and vocal communication.

When we distinguished between the different pointing situations, our results showed that hand preference for imperative pointing and declarative expressive pointing did not significantly differ from hand preference for grasping (i.e., manipulative) actions, whereas declarative informative gestures tended to be more right-handed than grasping actions. Moreover, MHI for informative pointing was 0.70, whereas the indices for imperative and expressive gestures were 0.43 and 0.46 , figures similar to that reported in the study by Vauclair and Imbault (2009), where MHI for pointing gestures was 0.52. These differences did not reach statistical significance, but this could have been due to the small size of the samples on which the statistical tests were performed (due to some children not producing any pointing gestures in one of the situations).

Thus, overall, our results indicate that the production of informative pointing gestures is particularly lateralized to the left cerebral hemisphere. Although behavioral methods and measures of hand preference only provide an indirect view of brain processes, we can reasonably infer from our results that some specific networks in the left hemisphere are more highly activated in informative situations, possibly reflecting a higher degree of complexity. All pointing gestures were produced in order to direct the addressee's attention toward a referent, but they were used for different purposes in each of the three situations, and may have involved different social-cognitive abilities. The interpretation of infants' social behavior is a tough question; nevertheless, results of several studies (e.g., Camaioni, 1997; Liszkowski et al., 2008; Tomasello et al., 2007) suggest that imperative pointing gestures were produced in order to obtain a desired object, and relied on the child's understanding of the other person as a causal agent. In the declarative expressive situation, children directed the adult's attention to the exciting event with the aim of engaging with the adult and sharing interest in this event. In the declarative informative situation, children pointed because of the adult's relation to the hidden object, implying that they were aware of the adult's informational state. Moreover, informative pointing solely benefited the other person (Liszkowski et al., 2006). These cooperative abilities, which are of a key importance for the emergence of language, may be related to a stronger involvement of the left cerebral hemisphere. Furthermore, informative pointing has been regarded as the first step toward the development of human abilities to teach and instruct other people (Liszkowski, 2005; Warneken, Chen, \& Tomasello, 2006).

To summarize, declarative expressive pointing was found to be closer to imperative pointing, regarding visual behavior and hand preference, but closer to declarative informative pointing regarding vocalizations, hand shape and gesture duration. The development of declarative expressive pointing may therefore represent an intermediate stage between imperative and cooperative communication. It may be more complex than simply requesting an object, but less demanding than cooperating with and helping an adult. Moreover, we cannot totally exclude the possibility that declarative expressive gestures were produced with a goal other than sharing interest about a surprising event. It has ever been argued that declarative expressive pointing involved less complex social understanding than usually attributed to infants (e.g., Moore \& Corkum, 1994). Southgate, van Maanen, and Csibra (2007) have notably argued that these gestures have an interrogative function, that is, children point in order to provoke comments and learn about an event or object, rather than to share enthusiasm about it. In the same way that imperative pointing can be described as a request for an object, declar- 
ative expressive pointing may be tantamount to a request for a comment. This hypothesis naturally needs to be tested in experimental investigations, but it could explain the intermediate position of declarative expressive gestures in our results.

Finally, pointing is a complex gesture that is elicited in a variety of situations. The present study highlights the need for researchers to focus on a number of specific features, such as function, hand shape, vocalizations, gaze, and manual laterality, in order to fully investigate and understand this communicative behavior.

\section{Acknowledgements} data.

The authors would like to thank Maeva Herreng, Romina Imary and Delphine Larrouilh for their help in collecting the This research was supported by a French National Research Agency (ANR) grant, reference ANR-08-BLAN-0011_01.

\section{References}

Bates, E., Camaioni, L., \& Volterra, V. (1975). The acquisition of performatives prior to speech. Merrill-Palmer Quarterly, $21,205-226$.

Bates, E., O'Connell, B., Vaid, J., Sledge, P., \& Oakes, L. (1986). Language and hand preference in early development. Developmental Neuropsychology, 2, 1-15.

Blake, J., O'Rourke, P., \& Borzellino, G. (1994). Form and function in the development of pointing and reaching gestures. Infant Behavior and Development, $17,195-203$.

Butterworth, G., Franco, F., McKenzie, B., Graupner, L., \& Todd, B. (2002). Dynamic aspects of visual event perception and the production of pointing by human infants. British Journal of Psychology, 20, 1-24.

Butterworth, G., \& Morissette, P. (1996). Onset of pointing and the acquisition of language in infancy. Journal of Reproductive and Infant Psychology, 14, 219-231.

Brooks, R., \& Meltzoff, A. N. (2008). Infant gaze following and pointing predict accelerated vocabulary growth through two years of age: A longitudinal, growth curve modeling study. Journal of Child Language, 35, 207-220.

Camaioni, L. (1997). The emergence of intentional communication in ontogeny, phylogeny and pathology. European Psychologist, $2,216-225$.

Camaioni, L., Perucchini, P., Bellagamba, F., \& Colonnesi, C. (2004). The role of declarative pointing in developing a theory of mind. Infancy, 5, 291-308.

Camaioni, L., Perucchini, P., Muratori, F., \& Milone, A. (1997). Brief report: A longitudinal examination of the communicative gestures deficit in young children with autism. Journal of Autism and Developmental Disorders, 27, 125-715.

Carpenter, M., Nagell, K., \& Tomasello, M. (1998). Social cognition, joint attention, and communicative competence from 9 to 15 months of age. Monographs of the Society for Research in Child Development, 255(63), 1-143.

Cochet, H., \& Vauclair, J. (2010). Features of spontaneous pointing gestures in toddlers. Gesture, 10(1), 86-107.

Fenson, L., Dale, P., Reznick, S., Thal, D., Bates, E., Hartung, J., et al. (1993). MacArthur Communicative Development Inventories: User's guide and technical manual. San Diego: CA Singular Publishing Group.

Franco, F., \& Butterworth, G. (1996). Pointing and social awareness: Declaring and requesting in the second year. Journal of Child Language, 23, 307-336.

Gullberg, M., de Bot, K., \& Volterra, V. (2008). Gestures and some key issues in the study of language development. Gesture, 8, 149-179.

Heimann, M., Strid, K., Smith, L., Tjus, T., Ulvund, S. E., \& Meltzoff, A. N. (2006). Exploring the relation between memory, gestural communication and the emergence of language in infancy: Longitudinal study. Infant and Child Development, 15, 233-249.

Iverson, J. M., \& Goldin-Meadow, S. (2005). Gesture paves the way for language development. Psychological Science, 16, 367-371.

Kendon, A., \& Versante, L. (2003). Pointing by hand in Neapolitan. In S. Kita (Ed.), Pointing: Where language, culture, and cognition meet (pp. 109-137). Mahwah, NJ: Lawrence Erlbaum Associates.

Kern, S. (2003). Le compte rendu parental au service de l'évaluation de la production lexicale des enfants français entre 16 et 30 mois [Evaluation through parental report of lexical development in French children from 16 to 30 months]. Glossa, 85, 48-61.

Krause, M. A., \& Fouts, R. S. (1997). Chimpanzee (Pan troglodytes) pointing: Hand shapes, accuracy, and the role of eye gaze. Journal of Comparative Psychology, $111,330-336$.

Leavens, D. A. (2009). Manual deixis in apes and humans. In C. Abry, A. Vilain, \& J.-L. Schwartz (Eds.), Vocalize to localize (pp. 67-86). Amsterdam: Benjamins.

Leavens, D. A., Hopkins, W. D., \& Bard, K. A. (1996). Indexical and referential pointing in chimpanzees (Pan troglodytes). Journal of Comparative Psychology, $110,346-353$.

Liszkowski, U. (2005). Human twelve-month-olds point cooperatively to share interest with and helpfully provide information for a communicative partner. Gesture, 5(1-2), 135-154.

Liszkowski, U., Carpenter, M., Henning, A., Striano, T., \& Tomasello, M. (2004). Twelve-month-olds point to share attention and interest. Developmental Science, 7, 297-307.

Liszkowski, U., Carpenter, M., Striano, T., \& Tomasello, M. (2006). Twelve- and 18-month-olds point to provide information for others. Journal of Cognition and Development, 7, 173-187.

Liszkowski, U., Carpenter, M., \& Tomasello, M. (2007). Pointing out new news, old news, and absent referents at 12 months of age. Developmental Science, $10,1-7$.

Liszkowski, U., Carpenter, M., \& Tomasello, M. (2008). Twelve-month-olds communicate helpfully and appropriately for knowledgeable and ignorant partners. Cognition, 108, 732-739.

Moore, C., \& Corkum, V. (1994). Social understanding at the end of the first year of life. Developmental Review, 14, 349-372.

Moore, C., \& D'Entremont, B. (2001). Developmental changes in pointing as a function of attentional focus. Journal of Cognition E Development, 2, 109-129.

O’Neill, M., Bard, K. A., Linnell, M., \& Fluck, M. (2005). Maternal gestures with 20-month-old infants in two contexts. Developmental Science, 8, $352-359$.

Pika, S. (2008). Gestures of apes and pre-linguistic human children: Similar or different? First Language, 28, $116-140$.

Pizzuto, E., \& Capobianco, M. (2005). The link and differences between deixis and symbols in children's early gestural-vocal system. Gesture, 5(1/2), 179-199.

Racine, T. P., \& Carpendale, J. I. M. (2007). The role of shared practice in joint attention. British Journal of Developmental Psychology, $25,3-25$.

Rowe, M. L., \& Goldin-Meadow, S. (2009). Early gesture selectively predicts later language learning. Developmental Science, $12,182-187$.

Southgate, V., van Maanen, C., \& Csibra, G. (2007). Infant pointing: Communication to cooperate or communication to learn? Child Development, 78(3), $735-740$.

Tomasello, M. (1995). Joint attention as social cognition. In C. Moore, \& P. J. Dunham (Eds.), Joint attention: Its origin and role in development (pp. 103-130). Hillsdale, New York: Erlbaum.

Tomasello, M., \& Call, J. (1997). Primate cognition. New York: Oxford University Press.

Tomasello, M., Carpenter, M., \& Liszkowski, U. (2007). A new look at infant pointing. Child Development, 78, 705-722.

Vauclair, J., \& Imbault, J. (2009). Relationships between manual preferences for manipulative actions and for pointing gestures in infants and toddlers. Developmental Science, 12, 1060-1069.

Vygotsky, L. S. (1988). Development of the higher mental functions. In K. Richardson, \& S. Sheldon (Eds.), Cognitive development in adolescence (pp. 61-80). Hove: Lawrence Erlbaum. 
Warneken, F., Chen, F., \& Tomasello, M. (2006). Cooperative activities in young children and chimpanzees. Child Development, 77, 640-663.

Wilkins, D. (2003). Why pointing with the index finger is not a universal (in sociocultural and semiotic terms). In S. Kita (Ed.), Pointing: Where language, culture, and cognition meet (pp. 171-215). Mahwah, NJ: Lawrence Erlbaum Associates.

Young, A. M., Lock, A. J., \& Service, V. (1985). Infants' hand preferences for actions and gestures. Developmental Neuropsychology, 1, 17-27. 